13,18

\title{
Структура и устойчивость дефектного силицена на подложках (001) Ag и (111) Ag: компьютерный эксперимент
}

\author{
(c) А.Е. Галашев, К.А. Иваничкина, А.С. Воробьев, О.Р. Рахманова \\ Институт высокотемпературной электрохимии УрО РАН, \\ Екатеринбург, Россия \\ E-mail: galashev@ihte.uran.ru
}

(Поступила в Редакцию 18 июля 2016 г.

В окончательной редакции 12 декабря 2016 г.)

\begin{abstract}
Методом молекулярной динамики исследована структура и устойчивость двухслойного дефектного силицена на подложках $\mathrm{Ag}(001)$ и $\mathrm{Ag}$ (111). Трансформация функции радиального распределения силицена, происходящая за счет формирования моно-, би-, три- и гексавакансий, в основном сводится к уменьшению интенсивности пиков и исчезновению „плеча“ на втором пике. Со временем может происходить объединение поливакансий, а также их деление и формирование вакансионных кластеров. Согласно геометрическому критерию, подложка $\mathrm{Ag}$ (001) обеспечивает бо́льшую устойчивость совершенного двухслойного силицена. Однако более низкое значение энергии дефектного силицена на этой подложке наблюдается только при наличии в нем моно- и бивакансий. Изменение размера дефектов создает смену энергетического приоритета в выборе между подложками $\mathrm{Ag}(001)$ и $\mathrm{Ag}$ (111). Движение иона лития по расширенному каналу между двумя листами силицена приводит к дальнейшему разупорядочению дефектной структуры силицена, при этом наиболее сильные напряжения в силицене создаются силами, направленными перпендикулярно напряженности внешнего электрического поля. Эти силы доминируют в силиценовом канале, стенка которого поддерживается подложкой $\mathrm{Ag}(001)$ или $\mathrm{Ag}(111)$.
\end{abstract}

Исследование выполнено за счет гранта Российского научного фонда (проект № 6-13-00061).

DOI: 10.21883/FTT.2017.06.44496.300

\section{1. Введение}

Электронная структура силицена аналогична структуре графена в том, что края зон (проводимости и валентной) встречаются в углах (точках $K$ и $K^{\prime}$ ) зоны Бриллюэна. Силицен может легче трансформироваться, как химически, так и структурно, по сравнению с графеном. К настоящему времени силицен был получен на подложках: $\mathrm{Ag}$ (111) [1,2], $\mathrm{ZrB}_{2}$ (0001) [3], $(2 \times 1)$-реконструированном Au (110) [4] и $\operatorname{Ir}(111)$ [5]. Также были получены графеноподобные силиценовые наноленты на поверхностях $\mathrm{Ag}$ (001) и $\mathrm{Ag}$ (110) [6]. Дефекты часто являются доминирующим фактором в применении двумерных материалов. Дефекты, такие как вакансии, легко индуцируются лазерным излучением или электронным пучком. Они почти неизбежны при изготовлении и обработке монослойных материалов. Кроме того, небольшие дефекты могут быть введены для конкретных применений [6,7]. Например, с помощью создания или устранения точечных дефектов можно провести настройку локальной структуры, изменить термическую стабильность, а также регулировать величину запрещенной зоны низкоразмерных материалов [8-11]. Также хорошо известно, что двумерные материалы с дефектами являются превосходными мембранами для разделения газов [12,13]. Структура и энергетика точечных дефектов в свободно стоящем силицене исследовалась в работах [10-15]. Например, в работе [10] изучались атомистические механизмы самовосстановле- ния вакансионных дефектов, и было обнаружено, что процесс восстановления происходит за счет энергии, полученной в результате формирования новых связей $\mathrm{Si}-\mathrm{Si}$ В работе [9] были исследованы структура, энергия образования и поведение при миграции типичных монои бивакансий. Вакансионные дефекты, образующиеся в ходе локальных структурных изменений, значительно снижают термическую устойчивость силицена [14]. Ранее выполненные исследования, как правило, сосредоточенные на изучении механизмов формирования одно-, двух- и трехместных дефектов, углубили понимание диффузии вакансий в силицене. Недавние экспериментальные исследования показали, что большое количество дефектов в форме кластеров с более, чем тремя недостающими атомами кремния присутствуют в микроскопических изображениях, полученных с помощью сканирующей туннельной микроскопии [15]. Хотя наличие многоатомных вакансий имеет фундаментальное значение для понимания формирования и функционирования слоистых материалов, механизм их зарождения не полностью раскрыт. Эта проблема решалась методом расчетов по теории функционала плотности с упором на изучение реконструкции, слипания и диффузии вакансионных дефектов в свободно стоящем силицене [16]. Была исследована адсорбция и диффузия атомов кремния в пределах силиценовых слоев, приводящая к открытию значительной части запрещенной зоны в силицене. До настоящего времени не было проведено никаких исследований в отношении устойчивости дефектного силице- 
на на подложках. При этом интерес представляют именно те подложки, на которых силицен удается получить экспериментально.

Представляется перспективным изменять электронную структуру силицена путем создания в нем дефектов. Вакансии или поливакансии можно формировать в силицене путем его ионной бомбардировки. Нескомпенсированные связи у атомов $\mathrm{Si}$, расположенных на краях вакансий (поливакансий), притягивают к себе электрические заряды, тем самым изменяя электронные свойства силицена. Удерживание отрицательных зарядов на границах вакансий приводит к образованию областей $n$-типа, положительные же заряды вблизи этих дефектов формируют области $p$-типа. Имея на границах вакансий как отрицательные, так и положительные заряды, можно на одном и том же листе силицена сформировать переходы $p$ - и $n$-типов. Количество зарядов на каждом дефекте можно регулировать путем изменения размера поливакансии, например, переходя от моно-, би- и тривакансий к гексавакансиям.

Если силицен не способен существовать как самостоятельная фаза, то и его применение возможно только вместе с поддерживающей его подложкой. Одним из наиболее важных направлений использования силицена является его применение в качестве анода литий-ионных батарей. Это связано с высокой теоретической литиевой емкостью кремния (6 атомов $\mathrm{Li}$ на один атом $\mathrm{Si}$ ), относительно небольшим изменением объема (13\% и $24 \%$ для одно- и двухслойного силицена соответственно) при литиировании силицена и полным восстановлением его структуры в результате делитиирования [17].

Цель настоящей работы - изучить устойчивость двухслойного силицена, насыщенного моно-, би, триили гексавакансиями, на подложках $\mathrm{Ag}$ (001) и $\mathrm{Ag}$ (111) в отсутствие зарядов на их границах. Мы также рассматриваем прохождение иона $\mathrm{Li}^{+}$в постоянном электрическом поле между листами силицена с дефектами такого типа.

\section{2. Компьютерная модель}

Расчеты выполнены методом классической молекулярной динамики (МД). За основу представления взаимодействий в силицене взят потенциал Терсоффа с параметрами из работы [18]. Потенциальная функция для силицена $U_{\mathrm{Si}-\mathrm{Si}}$ определена в виде

$$
U_{\mathrm{Si}-\mathrm{Si}}=\sum_{i, j>i}\left\lfloor V_{i j}^{R}\left(r_{i j}\right)-b_{i j}\left(\xi\left(\mathbf{r}, \theta_{i j k}^{B}\right)\right) V_{i j}^{A}\left(r_{i j}\right)\right\rfloor,
$$

где $r_{i j}$ - расстояния между атомами $i$ и $j$, функция $b_{i j}$ описывает многочастичное взаимодействие между связью $i-j$ и локальным окружением атома $i ; \xi-$ эффективное координационное число, $\theta_{i j k}^{B}-$ угол между векторами $\mathbf{r}_{i j}$ и $\mathbf{r}_{j k}$. Определение компонент потенциала, описывающих отталкивание $V_{i j}^{R}$ и притяжение $V_{i j}^{A}$, основано на использовании потенциала Морзе [19]. Также

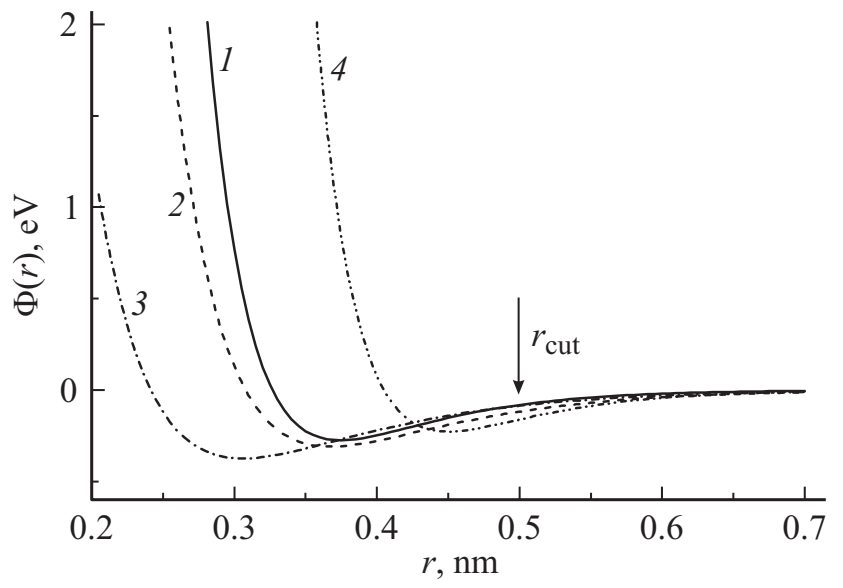

Рис. 1. Потенциал Морзе, описывающий взаимодействия: $1-\mathrm{Ag}-\mathrm{Si}, 2-\mathrm{Li}-\mathrm{Si}, 3-\mathrm{Li}-\mathrm{Ag}, 4-\mathrm{Si}-\mathrm{Si}$ между слоями силицена.

потенциалом Морзе описывалось взаимодействие между атомами $\mathrm{Si}$, принадлежащими разным листам силицена [20], между атомами $\mathrm{Si}$ и $\mathrm{Ag}[19,20]$ и взаимодействие между ионом $\mathrm{Li}^{+}$и атомами $\mathrm{Si}$ и $\mathrm{Ag}$ [21-22]. Потенциал Морзе, используемый для представления этих взаимодействий показан на рис. 1. Радиус обрезания используемого нами потенциала $r_{c u t}=0.5 \mathrm{~nm}$ соответствовал величине $r_{c u t}$ для потенциала Леннарда-Джонса, описывающего взаимодействие $\mathrm{Ag}-\mathrm{Si}$ в работе [23]. Варьирование радиуса обрезания потенциала в области $0.45-0.65 \mathrm{~nm}$ показало отсутствие существенной зависимости исхода моделирования движения иона по каналу от значения $r_{c u t}$. Значение потенциала Морзе в точке обрезания $(0.5 \mathrm{~nm})$ составляет от 20 до $40 \%$ от глубины соответствующей потенциальной ямы. Из-за обрезания радиуса взаимодействия каждый атом $\mathrm{Si}$ мог взаимодействовать с атомами $\mathrm{Ag}$ не более, чем из двух поверхностных слоев, при расстоянии между силиценом и подложкой $r_{\mathrm{Ag}-\mathrm{Si}}=0.27 \mathrm{~nm}$ [24]. Процедура обрезания взаимодействий позволяет эффективно учесть экранирование взаимодействий атомами полупроводника и атомами металла. Межслойный потенциал $\mathrm{Si}-\mathrm{Si}$ не подвергался обрезанию.

В настоящей работе мы рассматриваем случай реконструкции поверхности силицена $4 \times 4$. Единичная ячейка такой структуры содержит 18 атомов $\mathrm{Si}$. Шесть атомов $\mathrm{Si}$ единичной ячейки смещены на расстояние $0.065 \mathrm{~nm}$ перпендикулярно поверхности, а остальные атомы Si находятся на одной и той же (исходной) плоскости. Такая структура силиценового листа близка к поверхности силицена, наблюдаемой на подложке $\mathrm{Ag}(111)$ [24]. Если в верхнем листе двухслойного силицена выступающие над исходной поверхностью атомы смещены вверх, то в нижнем листе такие атомы выдвигаются вниз. Рассчитанный по теории функционала плотности зазор $h_{g}$ между листами двухслойного силицена с $A B$-укладкой составляет 
$0.2481 \mathrm{~nm}$ [25]. В случае продольного перемещения иона $\mathrm{Li}^{+}$использовались значения $h_{g}: 0.75,0.80$ и $0.85 \mathrm{~nm}$.

Лист совершенного силицена имел размеры $4.8 \times 4.1 \mathrm{~nm}($ с учетом размера атомов $\mathrm{Si}$ ) и содержал 300 атомов. Местоположения краевых атомов листов силицена и серебра были фиксированы, т. е. эти атомы взаимодействовали с остальными атомами, но не перемещались. Фиксирование краевых атомов создает условия для сохранения морфологии пористого силицена и отражает закрепление этого образца на рамке в физическом эксперименте. Ограниченные размеры листов позволяли надежно регистрировать их полное прохождение ионом лития в направлении приложенного электрического поля. Приблизительно равномерно и со смещением на $1-2 \mathrm{~nm}$ в каждом направлении ( $x$ и $y)$ для разных листов в силицене создавалось девять однотипных дефектов: моновакансий, бивакансий, тривакансий и гексавакансий. Соответственно, листы силицена содержали 291, 282, 273 и 246 атомов. Силиценовые листы располагались в соответствии с укладкой Бернала $(A B A B \ldots)$ точно таким же способом, как в объемном графите. Двухслойный силицен размещался на нереконструированных поверхностях Ag (001) и Ag (111) ГЦК кристалла серебра.

Численное решение уравнений движения выполнялось методом Рунге-Кутты четвертого порядка с временным шагом $\Delta t=1 \cdot 10^{-16} \mathrm{~s}$. Длительность расчетов ограничивалась периодом $4 \cdot 10^{6} \Delta t(400 \mathrm{ps})$. Минимальный интервал усреднения (макрошаг) для получения наблюдаемых величин составлял $10^{4} \Delta t$ или $10 \mathrm{ps}$. Атомы $\mathrm{Ag}$ в 3.84 раза тяжелее атомов $\mathrm{Si}$. Следовательно, при столкновениях с атомами $\mathrm{Si}$ атомы $\mathrm{Ag}$ должны получать в такое же число раз меньшие скорости. Поэтому с хорошей точностью в вычислениях можно ограничиться приближением взаимодействующих, но не перемещающихся атомов $\mathrm{Ag}$.

В отдельных МД-расчетах подбиралось минимальное значение напряженности электрического поля, начиная с которого ион лития мог полностью проходить графеновый канал в направлении приложенного поля и покидать его через воображаемую заднюю поверхность. Поле напряженностью $10^{6} \mathrm{~V} / \mathrm{m}$ удовлетворяет этому условию. Высокая емкость электрода достижима при быстром перемещении ионов электролита так, чтобы коэффициент самодиффузии иона $D$ находился в интервале $10^{-10}-10^{-13} \mathrm{~cm}^{2} / \mathrm{s}$ [26]. При зазорах $h_{g}=0.80$ и $0.85 \mathrm{~nm}$ (для совершенного силицена) и $0.85 \mathrm{~nm}$ (для силицена с дефектами) коэффициент $D$ иона лития при горизонтальном движении иона по каналу попадает в этот интервал значений, когда напряженность электрического поля составляет $10^{6} \mathrm{~V} / \mathrm{m}$. Такое поле не может оказать существенного влияния на параметры электронных орбит атомов, а, следовательно, внести изменения в широко используемые потенциалы межатомного взаимодействия. Это заключение можно сделать из следующих фактов. Изучение многократного рассеяния электронов в керамике $\mathrm{SrTiO}_{3}$ и передачи импульса электронов позволило получить количественные характеристики атомного электрического поля [27]. Вблизи атома кислорода измеренное зондом максимальное значение поля составило $4 \cdot 10^{11} \mathrm{~V} / \mathrm{m}$, а в окрестности атомов $\mathrm{Ti}$ и $\mathrm{Sr}-10^{12} \mathrm{~V} / \mathrm{m}$. Точность измерений определяется разрешающей способностью микроскопа. Поля с напряженностью $\sim 10^{10} \mathrm{~V} / \mathrm{m}$ могут оказывать значительное влияние на атомные орбитали. Поэтому их использование в классической молекулярной динамике некорректно. Следовательно, линейный отклик системы на внешнее поле следует ожидать при напряженностях менее $\sim 10^{10} \mathrm{~V} / \mathrm{m}$.

В начальный момент времени ион $\mathrm{Li}^{+}$был вдвинут в силиценовый канал на достаточно малое расстояние $(x=0.31 \mathrm{~nm})$ при $y=2.2 \mathrm{~nm}$. В случае зазоров $h_{g}=0.75$ и $0.80 \mathrm{~nm}$ ион $\mathrm{Li}^{+}$всегда застревал в канале, образованном дефектным силиценом. Ион $\mathrm{Li}^{+}$не выходил из силиценовых каналов, содержащих бивакансии, при зазоре $h_{g}=0.85 \mathrm{~nm}$ в течение всего расчета. В остальных случаях при этом зазоре ион проходил каналы, размещенные на подложках обоего типа, за 7-38 ps. При этом в среднем его абсолютная скорость $u_{a b s}$ составляла $3.59 \cdot 10^{-4} \mathrm{~cm}^{2} \mathrm{~V}^{-1} \mathrm{~s}^{-1}$ на подложке $\mathrm{Ag}(001)$ и $3.51 \cdot 10^{-4} \mathrm{~cm}^{2} \mathrm{~V}^{-1} \mathrm{~s}^{-1}$ на подложке $\mathrm{Ag}$ (111). В водном растворе при $298 \mathrm{~K}$ ион $\mathrm{Li}^{+}$имеет $u_{a b s}=3.88 \cdot 10^{-4} \mathrm{~cm}^{2} \mathrm{~V}^{-1} \mathrm{~s}^{-1}$. Во всех рассмотренных случаях движение иона лития носило диффузионный характер. Баллистический характер его движения мог наблюдаться при значениях $h_{g}>1 \mathrm{~nm}$.

Шероховатость поверхности (или среднее арифметическое отклонение профиля) вычислялась как [28]

$$
R_{a}=\frac{1}{N}\left\langle\sum_{i=1}^{N}\left|z_{i}-\bar{z}\right|\right\rangle
$$

где $N$ - число узлов (атомов) на листе силицена, угловые скобки обозначают усреднение по времени, $z_{i}-$ смещение атома $i$ в направлении оси $o z, \bar{z}-$ среднее значение координаты $z$ для силицена, величины $z_{i}$ и $\bar{z}$ определяются в один и тот же момент времени.

Для расчета напряжений, возникающих в силицене, листы полупроводника разбивались на элементарные площадки. Расчетная формула для определения локального напряжения имеет вид [29]

$$
\sigma_{u \alpha}(l)=\left\langle\sum_{i}^{k} \frac{1}{\Omega}\left(m v_{u}^{\prime} v_{\alpha}^{\prime}\right)\right\rangle+\frac{1}{S_{1}}\left\langle\sum_{1}^{k} \sum_{j \neq i}^{\left(u_{i} \leq u, u_{j} \geq u\right)}\left(f_{i j}^{\alpha}\right)\right\rangle .
$$

Здесь $k$ - количество атомов на площадке с номером $l$, $\Omega$ - объем, приходящийся на атом, $m-$ масса атома, $v_{\alpha}^{\prime}$ - компонента $\alpha$ скорости атома $i, S_{l}$ - площадь площадки $l . f_{i j}^{\alpha}$ - компонента $\alpha$ силы, дейстующей на площадку $l$. Пределы суммирования по $j$ во втором слагаемом в выражении (3) означают, что прямая, вдоль которой направлена сила взаимодействия атомов $i$ и $j$, пересекает плоскость, содержащую площадку $l ; u$ кордината точки пересечения. 
В расчетах использовался модифицированный нами код LAMMPS для параллельных вычислений методом МД [30]. Были введены фрагменты программы для расчета кинетических и механических свойств системы. Расчеты выполнены на гибридном вычислителе кластерного типа „УРАН“ при ИММ УрО РАН с пиковой производительностью $216 \mathrm{Tflop} / \mathrm{s}$ и включает в себя 1864 CPU.

\section{3. Результаты расчета}

Общий вид системы „двухслойный силицен с бивакансиями на $\mathrm{Ag}$ (001)“ после 4000000 временных шагов (400 ps) показан на рис. 2. Видно, что в ходе расчета происходят заметные вертикальные смещения атомов $\mathrm{Si}$ как в верхнем, так и в нижнем листе силицена. Причем при переходе от силицена с моновакансиями к силицену с гексавакансиями величина смещений увеличивается. Аналогичная картина наблюдается для системы с подложкой $\mathrm{Ag}$ (111). При наличии той и другой подложки происходят также перестройки атомов $\mathrm{Si}$ в плоскости верхнего и нижнего листов силицена.

Область определения функции радиального распределения (ФРР) ограчивалась двумя координационными сферами. ФРР каждого дефектного листа силицена вне зависимости от используемой подложки имеет меньшую интенсивность пиков, отражающих присутствие первых соседей и соседей второго порядка, чем соответствующая ФРР для совершенного силицена (рис. 3). Рассчитанные функции радиального распределения получены путем усреднения на последнем из четырех временных интервалов с длительностью 100 ps, т.е. за период, составляющий 1/4 всего МД расчета. Для сравнения с ФРР совершенного силицена, имеющего подложку $\mathrm{Ag}(001)$, на рис. 3, $a$ представлена $g(r)_{\mathrm{Si}-\mathrm{Si}}$,

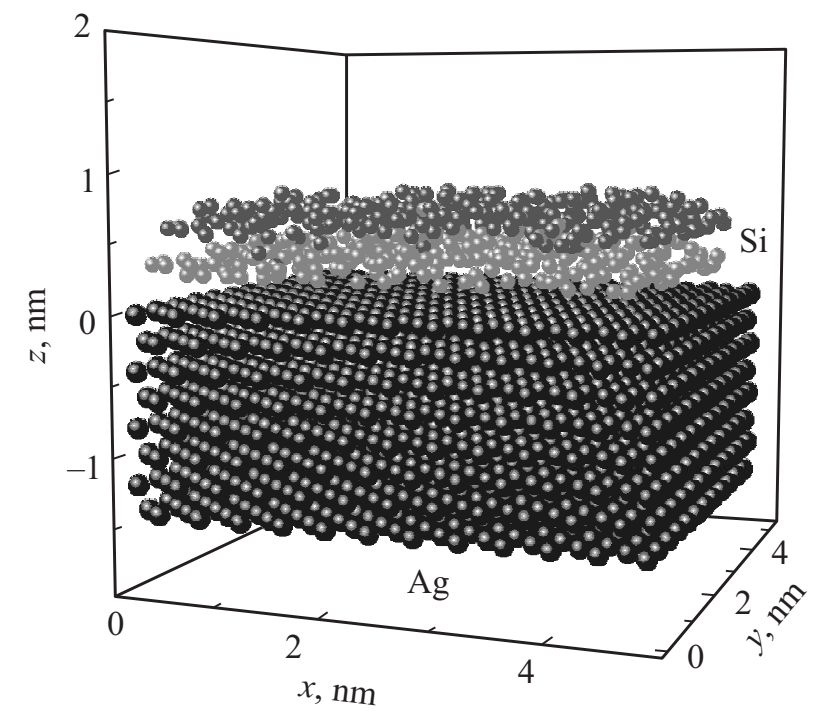

Рис. 2. Конфигурация системы „двухслойный силицен на подложке $\mathrm{Ag}(001)^{)}$, полученная к моменту времени 400 ps.

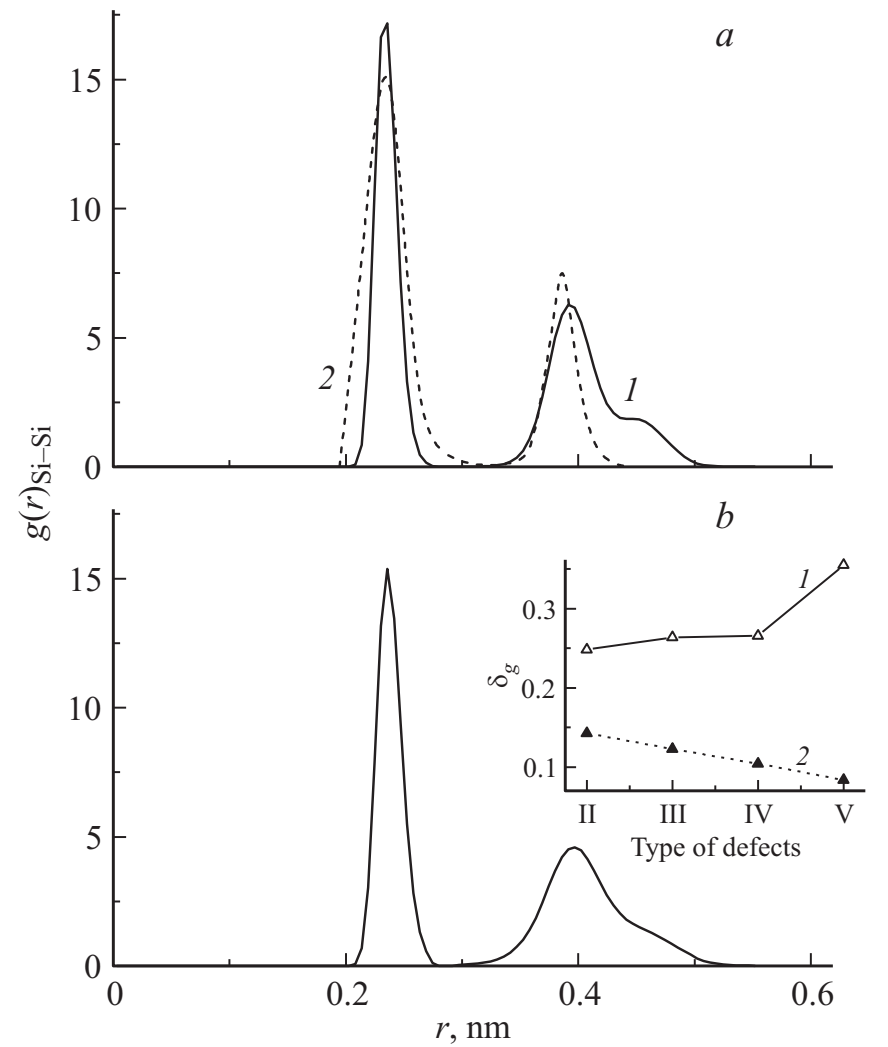

Рис. 3. Функции радиального распределения: (a) $1-$ совершенного силицена на подложке Ag (001) (усреднена по листам силицена), 2 - свободно стоящего плоского силицена [31] (b) силицена с тривакансиями на подложке $\mathrm{Ag}$ (001). На вставке - характеристика уменьшения интенсивности пиков ФРР: 1 - первого пика, 2 - второго пика.

полученная для плоской модели свободно стоящего силицена [31] с параметрами леннард-джонсовского потенциала, подогнанными по данным МД моделирования с потенциальной функцией Стиллинжера-Вебера [32]. Плотность „Плоского“ силицена на 24\% выше, чем плотность моделируемого здесь совершенного силицена на подложке Ag (001). Получены очень близкие местоположения первых пиков этих функций, в то время как местоположение второго пика ФРР „плоского“ силицена смещено на $2.5 \%$ в сторону коротких расстояний. Кроме того, ФРР „Плоского“ силицена имеет более низкий первый пик и более высокий и узкий второй пик. На рис. 3, $b$ показана ФРР нижнего листа силицена с тривакансиями при наличии подложки $\mathrm{Ag}$ (001). Второй пик $g(r)$ совершенного силицена имеет „плечо“ справа, которое размывается для ФРР дефектного силицена. Образование „плеча“ и значительное уширение пиков указывает на существенные вертикальные смещения атомов $\mathrm{Si}$ в модели. Введем следующие обозначения для исследуемых систем: I - бездефектный силицен, II - силицен с моновакансиями, III - с бивакансиями, IV - c тривакансиями и V - с гексавакансиями. Относительное уменьшение интенсивности первого пика 


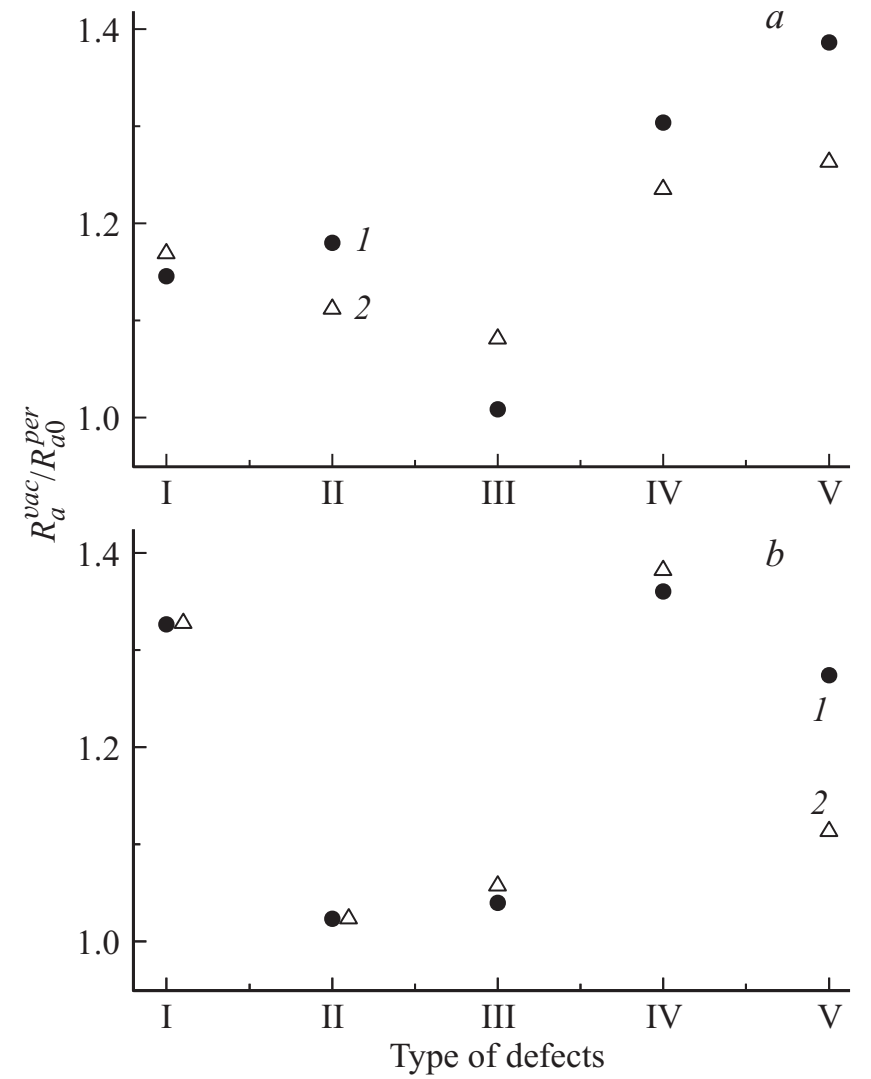

Рис. 4. Относительная шероховатость листов дефектного силицена $(1-$ нижний лист, 2 - верхний лист) на подложках: (a) - $\mathrm{Ag}$ (001), (b) - $\mathrm{Ag}(111)$.

ФРР $\delta_{g}=\left(g_{1}^{\mathrm{I}}-g_{1}^{j}\right) / g_{1}^{\mathrm{I}}(1-$ номер пика, $j$ обозначает систему) медленно нарастает при переходе от силицена с моновакансиями к силицену с би- и тривакансиями, и быстро возрастает для листов $\mathrm{Si}$ с гексавакансиями (вставка на рис. $3, b$ ). Аналогичная характеристика для интенсивности второго пика этой функции ведет себя противоположным образом, монотонно сокращаясь от систем с моновакансиями к силицену с гексавакансиями.

На рис. 4 показана относительная шероховатость $R_{a}^{v a c} / R_{a 0}^{p e r}$ дефектных листов силицена с различными типами вакансий. Шероховатость бездефектного силицена в исходном состоянии обозначена $R_{a 0}^{p e r}$. Данные, полученные для систем с подложкой $\mathrm{Ag}$ (001), отражает рис. 4, $a$, а результаты для систем с подложкой $\mathrm{Ag}(111)$ - рис. 4, $b$. Как видно из рисунка, во всех случаях шероховатость дефектного силицена поднимается выше уровня начальной шероховатости совершенного силицена $\left(R_{a}^{v a c} / R_{a 0}^{p e r}>1\right)$. Заметим, что вследствие атомных взаимодействий и появления рифления шероховатость совершенного графена также несколько увеличивается. Шероховатость совершенного силицена на подложке $\mathrm{Ag}$ (001) ниже, чем на подложке $\mathrm{Ag}$ (111). В испытании с подложкой $\mathrm{Ag}$ (001) шероховатость верхнего листа силицена, как правило, ниже, чем величина шероховатости $R_{a}$ нижнего листа, за исключением варианта для силицена с бивакансиями. Когда используется подложка Ag (111), шероховатость листов дефектного силицена приблизительно одинакова, и только для силицена с гексавакансиями величина $R_{a}$ для нижнего листа выше. Таким образом, на каждом из листов силицена, независимо от типа подложки Ag, трии гексавакансии приводят к бо́льшей шероховатости, чем моно- и бивакансии.

Представление о динамике разрушения гексавакансий нижнего листа силицена дает рис. 5. На данном листе в начальный момент времени присутствовало семь отдельных гексавакансий и две соединенные вакансии такого же типа. К моменту времени 200 ps на этом листе силицена образовалось две сдвоенные поливакансии и семь отдельных вакансий разного типа. Два вакансионных кластера в верхней и нижней части листа сформировались к моменту времени 400 ps. Каждый из

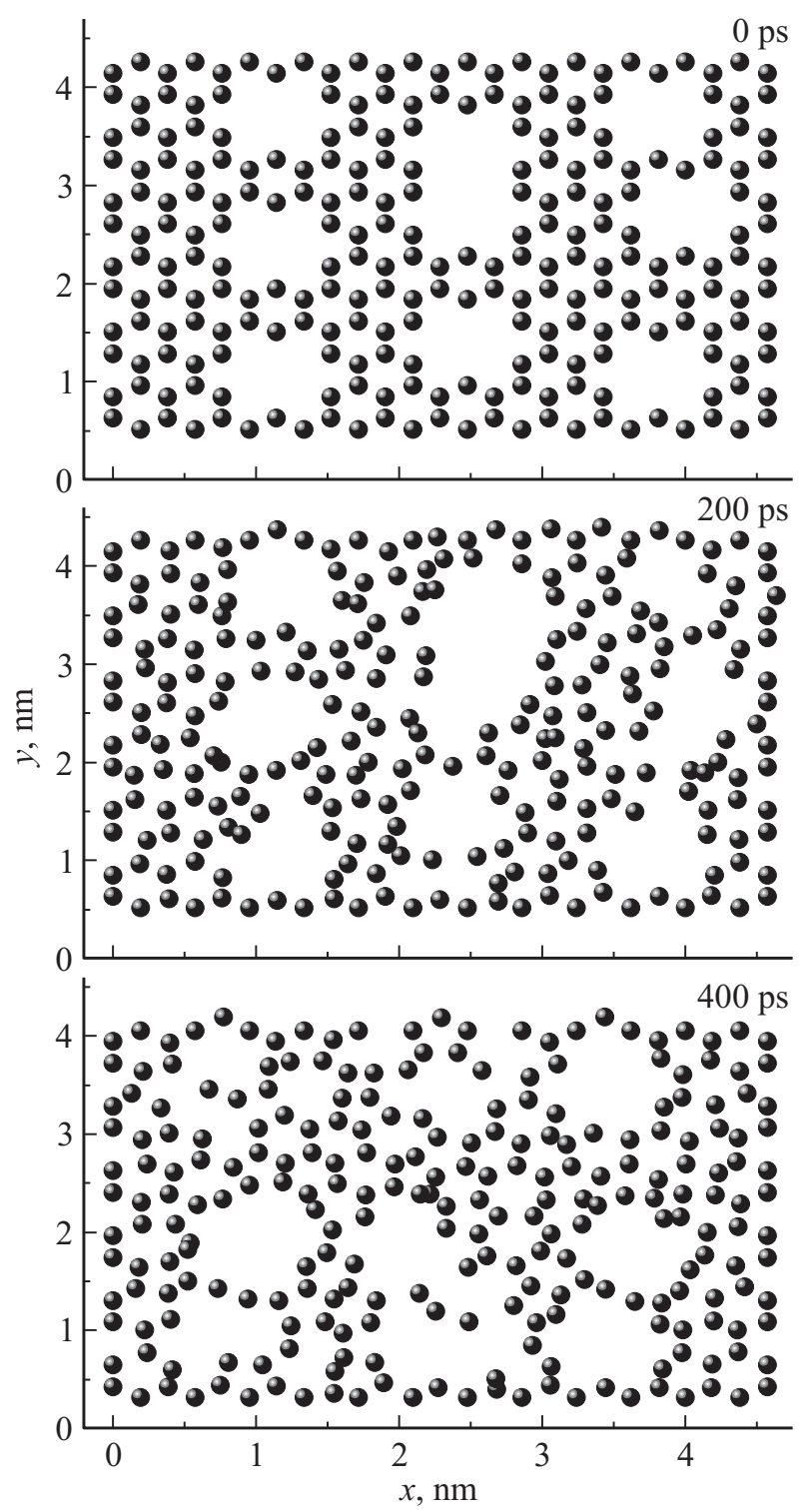

Рис. 5. Динамика разрушения гексавакансий в нижнем листе силицена, опирающегося на подложку Ag (111). 


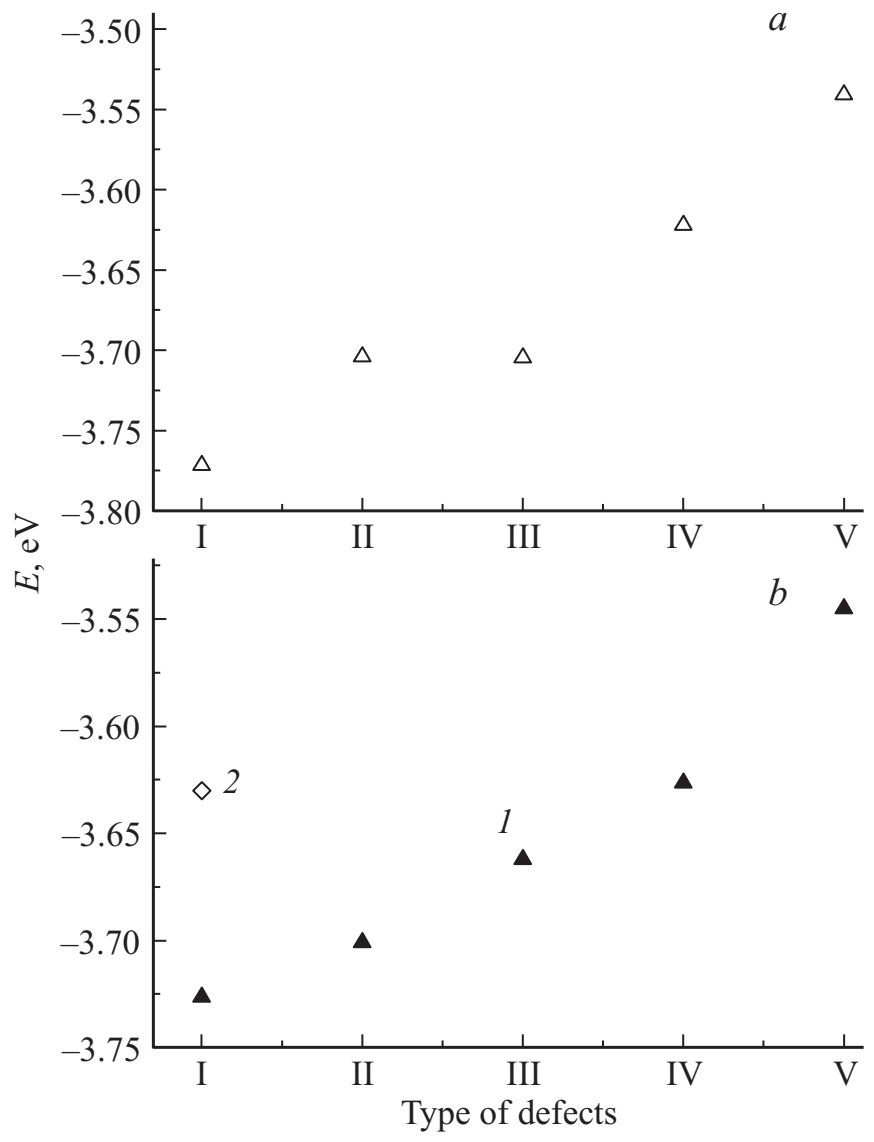

Рис. 6. Средняя внутренняя энергия $E$ листов силицена на подложках: (a) $\mathrm{Ag}$ (001), (b) $\mathrm{Ag}(111)$ в отсутствие дефектов система I: 1 - силицен, 2 - силиценовая полоса [33], и при наличии дефектов: II - моновакансий, III - бивакансий, IV - тривакансий, V — гексавакансий.

кластеров объединяет по восемь крупных и мелких пустот разного рода. Подобные структурные перестройки происходили как в нижнем, так и в верхнем листе силицена при наличии вакансий разного типа. В основном, наблюдалось дробление поливакансий на более мелкие и последующее их объединение в вакансионные кластеры.

Внутренняя энергия $E$ листов силицена, полученная для каждой из систем, показана на рис. 6. Рис. 6, $a$ относится к системам, имеющим подложку $\mathrm{Ag}(001)$, а pис. $6, b$ отражает энергию систем с подложкой $\mathrm{Ag}(111)$. В обоих случаях имеется тенденция к увеличению энергии $E$ по мере укрупнения вакансий в листах силицена. Основным различием поведения энергии $E$ систем с разными подложками является очень низкое значение этой характеристики для силицена с бивакансиями на подложке (001) $\mathrm{Ag}$, которое даже ниже энергии $E$ силицена с моновакансиями на идентичной подложке. Энергия совершенного силицена и силицена с моно- и бивакансиями на подложке $\mathrm{Ag}(001)$ ниже, чем соответствующая величина для силицена на подложке $\mathrm{Ag}$ (111). Однако при наличии в силицене три- и гексавакансий соотношение между энергиями изменяется на прямо противоположное. Для сравнения на рис. $6, b$ приведено оценочное значение энергии когезии бесконечной полосы силицена, не имеющей подложки [33]. Это значение заметно выше полученных нами значений $E$ совершенного силицена как на одной, так и на другой подложке. Заметим, что рассматриваемые здесь значения $E$ для силицена существенно выше экспериментального значения энергии алмазоподобного кремния $(-4.63 \mathrm{eV} / \mathrm{atom})$.

Нахождение иона $\mathrm{Li}^{+}$в канале приводит к постепенному разрушению ячеечной структуры силицена, особенно сильно это проявляется в силицене с поливакансиями. Распределение напряжений по длине канала с зазором $0.75 \mathrm{~nm}$ в нижнем листе силицена, лежащем на поверхности $\mathrm{Ag}$ (111), при наличии в нем гексавакансий показано на рис. 7. Картины распределения напряжений в верхнем и нижнем листах силицена во всех случаях оказываются похожими. Именно при наличии в листах силицена гексавакансий было получено самое сильное локальное напряжение $\sigma_{z y}$ при испытаниях с зазором $0.75 \mathrm{~nm}$. Всплески напряжений ближе к средней части длины листов вызваны присутствием иона в этих областях канала. Примечательно, что напряжения $\sigma_{z z}$,

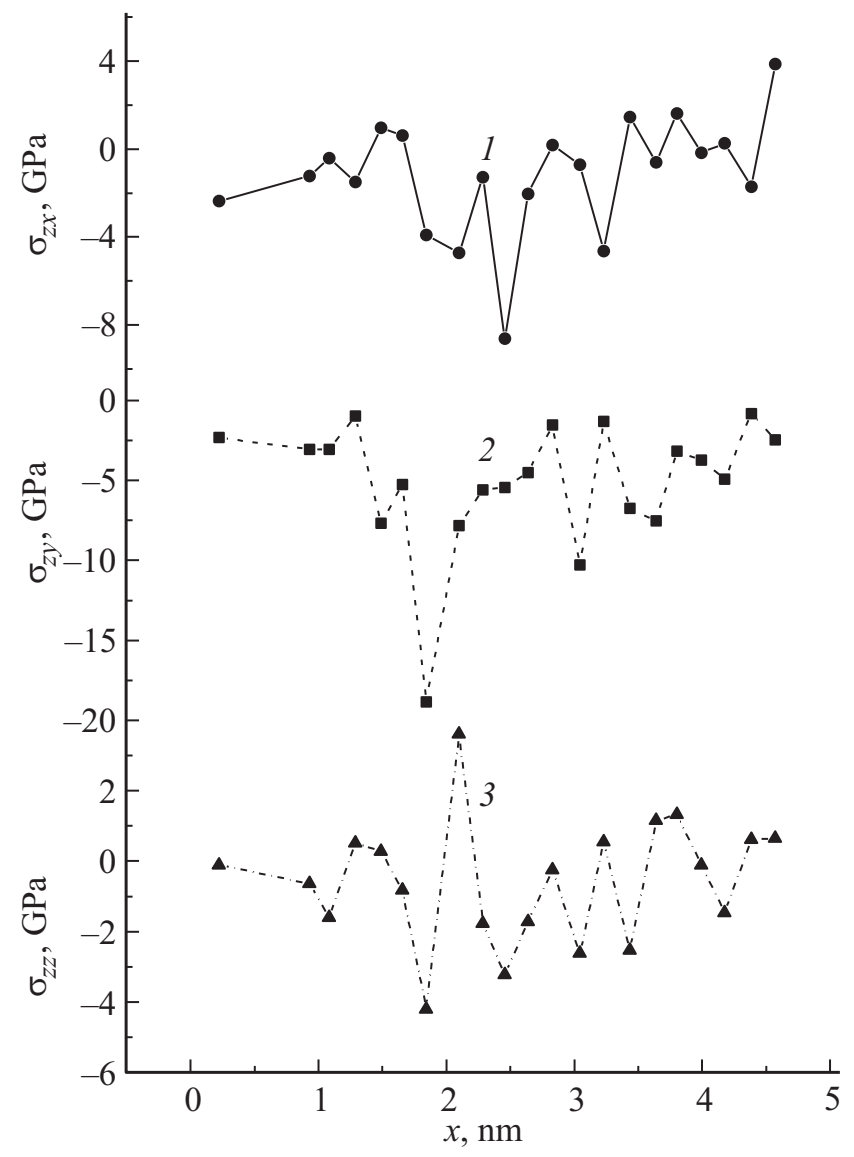

Рис. 7. Распределение напряжений: $1-\sigma_{z x}, 2-\sigma_{z y}$ и $3-\sigma_{z z}$, действующих в плоскости нижнего листа силицена, содержащего гексавакансии и находящегося на подложке $\mathrm{Ag}$ (111), при движении в плоском силиценовом канале иона $\mathrm{Li}^{+}$под действием электростатического поля. 
вызванные силами вертикального направления, как правило, оказываются значительно ниже напряжений $\sigma_{z x}$ и $\sigma_{z y}$, связанных с горизонтальными силами.

Максимальные абсолютные значения рассматриваемых выше напряжений, полученные как средние на временном макрошаге (10 ps), для всех исследуемых силиценовых каналов показаны на рис. 8. Как видно, ориентация поверхности подложки в большей степени оказывает влияние на величину $\left|\sigma_{z z}\right|_{\max }$, особенно в присутствии в листах силицена моно- и бивакансий. Самое большое значение $\left|\sigma_{z z}\right|_{\max }$ достигается в совершенном силицене на подложке $\mathrm{Ag}$ (001). На этой же подложке достигается максимальное абсолютное значение $\left|\sigma_{z x}\right|_{\max }$, что соответствует случаю присутствия в силицене гексавакансий. Также при наличии в силицене гексавакансий наблюдается максимальное значение величины $\left|\sigma_{z y}\right|_{\max }$ (приблизительно одинаковое на обеих подложках). Через ион $\mathrm{Li}^{+}$силицену передается внешнее воздействие, когда электростатическая сила действует вдоль оси $o x$. Однако наибольшие напряжения в силицене появляются благодаря силам, действующим в перпендикулярном

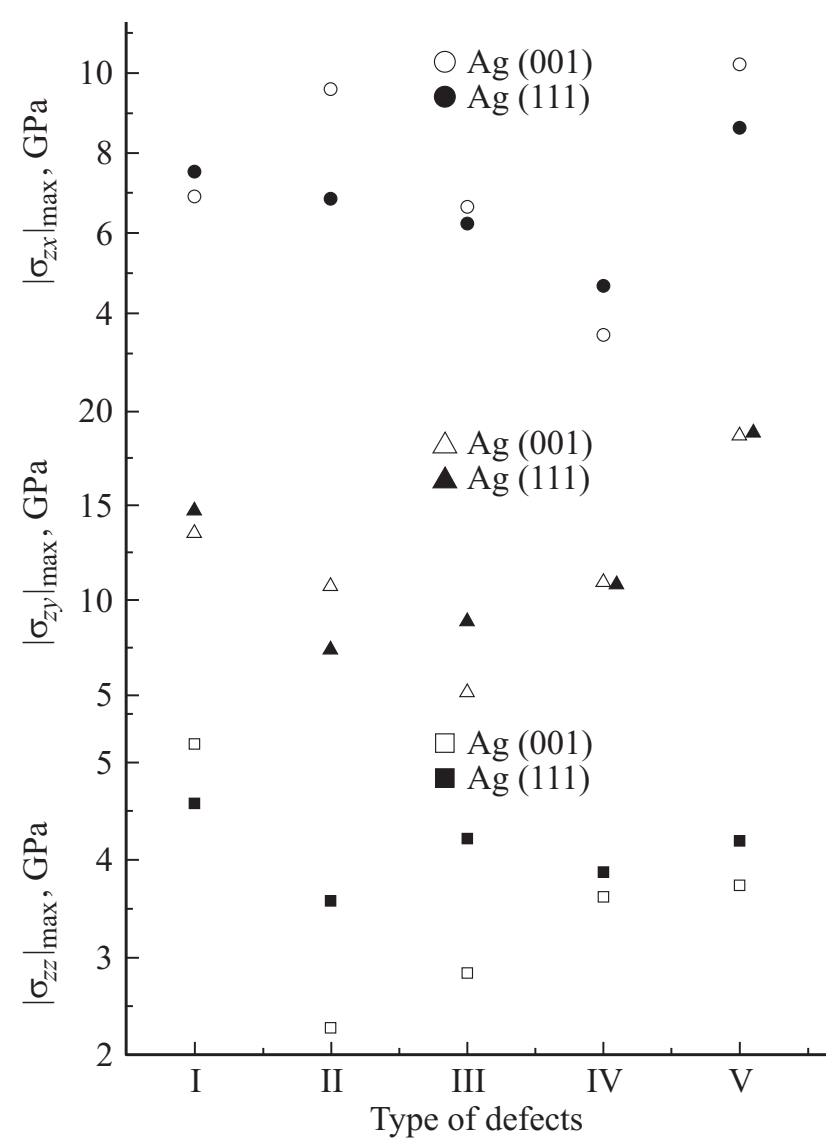

Рис. 8. Максимальные абсолютные значения локальных напряжений в нижних листах силицена, размещенных на подложках $\mathrm{Ag}(001)$ и $\mathrm{Ag}(111)$, при движении в плоском силиценовом канале иона $\mathrm{Li}^{+}$под действием электростатического поля. Рассматриваемые листы силицена: I - бездефектный, II - c моновакансиями, III - c бивакансиями, IV - c тривакансиями и $\mathrm{V}$ - с гексавакансиями.

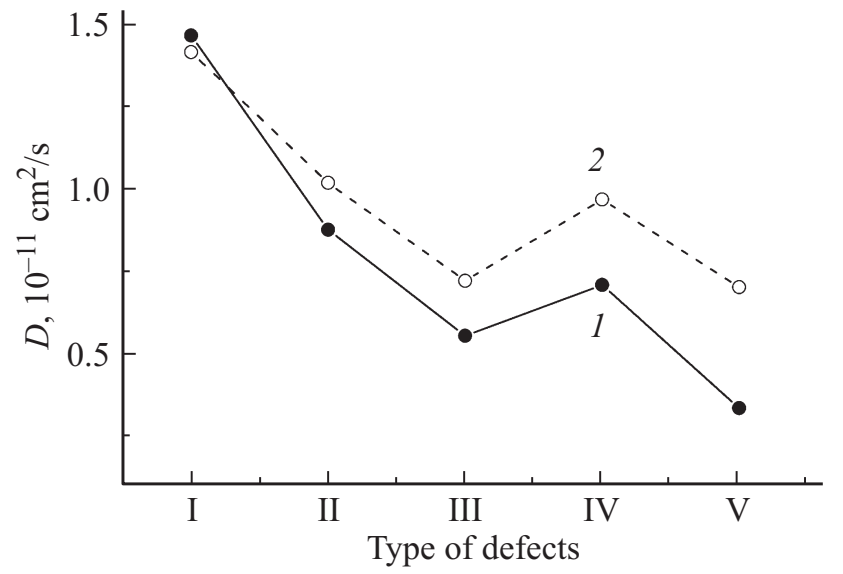

Рис. 9. Коэффициент самодиффузии, отражающий движение иона в силиценовых каналах: 1 - на подложке $\mathrm{Ag}(001), 2-$ на подложке $\mathrm{Ag}$ (111). Канал формировался листами силицена: I - бездефектным, II - c моновакансиями, III - c бивакансиями, IV - с тривакансиями и V - с гексавакансиями.

направлении (вдоль оси оу) и приводящим к его сжатию. Деформируемый двухслойный силицен имеет положительный коэффициент Пуассона.

Рассчитанные через средние квадраты смещения иона значения коэффициента самодиффузии $D$ для $\mathrm{Li}^{+}$, движущегося между листами силицена, один из которых находится на подложке $\mathrm{Ag}$ (001) или $\mathrm{Ag}$ (111), показаны на рис. 9. В обоих случаях коэффициент $D$ уменьшается с увеличением размера дефектов в силицене. Однако снижение $D$ не является монотонным, что в значительной степени связано со случайным характером процесса самодиффузии. Как на подложке $\mathrm{Ag}$ (001), так и на $\mathrm{Ag}$ (111) наблюдались локальные минимумы величины $D$, если в силицене присутствовали бивакансии. В обоих случаях диффузия иона проходила наиболее медленно, когда силиценовый канал был насыщен гексавакансиями. Значения $D$ в этом варианте минимальны, и для канала на поверхности $\mathrm{Ag}(001)$ он ниже, чем на поверхности Ag (111).

\section{4. Обсуждение результатов}

Подложка из серебра оказывает существенное влияние на устойчивость двухслойного силицена, особенно в случаях присутствия в нем вакансий и поливакансий. Представляет интерес сравнить поведение силицена при контакте с металлом с соответствующим поведением графена. Очевидно, что как и при взаимодействии графена с металлической поверхностью (например, медью), влияние тесного контакта материалов должно быть взаимным. В случае контакта медь/графен пленка металла испытывает значительные напряжения, наибольшими из которых являются $\sigma_{x x}, \sigma_{x y}$ и $\sigma_{y y}$ [34]. В графене наблюдается значительно более медленная релаксация напряжений, чем в металле [8]. Компоненты тензора 
напряжений медной пленки, отражающие действие сил на горизонтальную площадку, имеют принципиально разное поведение в случаях нахождения пленки на одноили двухслойном графене [35]. Если требуется снять пленку меди с графена, то целесообразно это сделать с помощью кластерного аргонового пучка, имеющего направление, параллельное плоскости листа графена [36]. В этом случае разрушающее действие на графен будет минимальным. В зависимости от области применения следует подбирать ту или иную технологию получения наноматериалов [37]. Повышение плотности свободных связей делает идентификацию структурных дефектов более надежной [38]. Диффузия, рассматриваемая в форме образования, взаимодействия и миграции дефектов, может проходить по типу эстафетной трансляции свободных связей.

В силицене наблюдается гораздо более сильное спинорбитальное взаимодействие, чем в графене. Атом $\mathrm{Si}$ имеет больший ионный радиус, чем атом С, и это способствует $s p^{3}$-гибридизации. Силицен способен формировать сильные связи с атомами металлов. Электронные и магнитные свойства силицена могут быть изменены за счет адсорбированных атомов. Энергия адсорбции лития на силицене достаточно велика, так что поверхность силицена вполне подходит для использования в литиевых батареях. Присутствие посторонних атомов может сильно изменить электронные свойства силицена. Так, если чистый силицен является полуметаллом, то при адсорбции других атомов он приобретает металлические свойства или свойства полупроводника.

Силицен и объемный кремний по-разному реагируют с кислородом. В кремнии кислород разрушает некоторые связи первых одного или двух атомных слоев. Сформированный кремнекислородный слой служит химическим барьером для предотвращения разрушения нижних слоев. Опираясь на эти факты можно предположить, что любое количество кислорода должно полностью разрушить однослойный силицен. Отсюда можно предположить, что формирование тонких пленок и чешуек кремния на поверхности серебра есть результат образования сплава. Следовательно, возможность существования силицена (не контактирующего с каким-либо материалом) должна быть показана прямым путем, т.е. его получением в условиях сверхвысокого вакуума при полном устранении взаимодействия с подложкой.

В работе [39] было достигнуто двухстадийное электрохимическое формирование совершенных слоев германена на поверхности $\mathrm{Au}$ (111). На первой стадии был получен монослой германия на подложке $\mathrm{Au}$ (111). Первый слой германия был прочно связан с подложкой и практически представлял собой сплав $\mathrm{Ge}_{x} \mathrm{Au}_{y}$ с различным содержанием компонентов $x$ и $y$. Вторая стадия заключалась в получении еще трех слоев гексагональной структуры германия на сформировавшейся подложке $\mathrm{Ge}_{x} \mathrm{Au}_{y}$. Германен в виде слоистой структуры в форме „пчелиных сот“ содержал дефекты. Таким образом, получение германена электрохимическим способом позво- лило экспериментально обнаружить образование сплава $\mathrm{Ge}_{x} \mathrm{Au}_{y}$ на подложке $\mathrm{Au}$ (111). Это во многом объясняет, почему до сих пор не удается экспериментально получить свободно стоящий германен или силицен.

Устойчивость системы, в которой отсутствует хемосорбция атомов $\mathrm{Si}$ на поверхности серебра, оказывается очень хрупкой. Склонность к $s p^{3}$-гибридизации создает предпосылку для смещения атомов $\mathrm{Si}$ многослойного силицена в направлении, перпендикулярном плоскости материала. Результаты настоящей работы показывают, что ослабленные присутствием дефектов вакансионного типа листы силицена сначала деформируются за счет вертикальных смещений атомов $\mathrm{Si}$, чему способствует взаимодействие иона $\mathrm{Li}^{+}$с атомами кремния. При этом связи $\mathrm{Si}-\mathrm{Si}$ еще больше ослабляются, и начинается постепенное разрушение точечных дефектов. Мелкие дефекты - моновакансии - могут затягиваться, образуя новые кольца из атомов $\mathrm{Si}$, как правило, с нечетным числом звеньев. Крупные поливакансии изменяют форму и размеры, тем самым провоцируя изменение структуры всего графенового листа, в котором структура в виде „пчелиных сот“ заменяется на аморфную структуру.

Подложка производит стабилизирующее действие при получении слоистых структур. Однако, в отсутствие хемосорбции, подложки $\mathrm{Ag}$ (001) и $\mathrm{Ag}$ (111) оказывают значительное дестабилизирующее влияние на устойчивость ячеечной структуры силицена, когда в нем присутствуют дефекты в виде вакансий и поливакансий. Ион $\mathrm{Li}^{+}$, двигающийся в электрическом поле между раздвинутыми в пределах $0.85 \mathrm{~nm}$ листами силицена, также способен разрушать ячеечную структуру, особенно, когда в ней присутствуют дефекты вакансионного типа. Поэтому использование двухслойного силицена в качестве анодного материала представляется весьма проблематичным, если он имеет большое число вакансий разного типа и не отделяется от подложек $\mathrm{Ag}(001)$ и $\mathrm{Ag}$ (111).

Точные измерения свойств материалов, находящихся на металлических подложках, выполнить очень трудно. Металлическая подложка экранирует внешнее электрическое поле и, по сути, лишает возможности манипулировать электронной структурой. По этой причине было бы желательно достигнуть состояния, какое имеет свободно стоящий силицен. Скорее всего, силицен в таком состоянии неустойчив по отношению к переходу в структуру кремния. Можно, однако, использовать надрешетку, которая стабилизирует двумерную структуру силицена, но имеет слабое взаимодействие с ним, не приводящее к возмущению дираковских состояний. Благодаря идентичной сотовой структуре сверхрешеткой для силицена может быть решетка гексагонального нитрида бора. Гексагональный нитрид бора является полупроводником с широкой запрещенной зоной и, следовательно, дает возможность изучения влияния внешнего перпендикулярного электрического поля, приложенного к силицену. Расчеты по теории функционала плотности показывают, что совокупный эффект собственного спин-орби- 
тального взаимодействия и внешнего электрического поля выражается в переходе от полуметалла к топологическому изолятору и далее к зонному диэлектрику [40].

\section{5. Заключение}

Методом молекулярной динамики исследована структура двумерного $\mathrm{Si}$ и устойчивость дефектов в двухслойном силицене на подложках $\mathrm{Ag}(001)$ и $\mathrm{Ag}$ (111). Coвершенный двухслойный силицен на подложке $\mathrm{Ag}$ (001) имеет более низкую энергию, чем его аналог на подложке $\mathrm{Ag}$ (111). Создание в силицене большого числа три- или гексавакансий может привести к обратному соотношению между энергиями силицена на этих подложках. Структурные перестройки, происходящие в двумерной системе, не сильно отражаются на форме функции радиального распределения силицена. Влияние подложек главным образом выражается в усилении вертикальных перемещений атомов $\mathrm{Si}$. Однако расширение зазора между листами силицена и пропускание между ними иона $\mathrm{Li}^{+}$в присутствии внешнего электрического поля значительно изменяет также горизонтальную проекцию двумерной структуры Si. Энергетические характеристики силицена на подложках Ag (001) и Ag (111) отличаются незначительно, за исключением системы с бивакансиями, для которой подложка $\mathrm{Ag}$ (001) более предпочтительна. Перемещение иона между листами силицена связано со значительными локальными флуктуациями напряжений, действующих в плоскости листов силицена. Причем, в большинстве случаев напряжения в совершенном силицене преобладают над соответствующими напряжениями в дефектном силицене. Главным исключением из этой закономерности является силицен с гексавакансиями, имеющий самые значимые напряжения $\sigma_{z y}$ на обоих типах подложек. Регулирование перемещения иона $\mathrm{Li}^{+}$с помощью электрического поля легче осуществлять в плоском канале, созданном из свободно стоящего силицена, чем в двухслойном силицене, находящемся на подложках Ag (001) или Ag (111). В этом случае также лучше сохраняются в силицене дефекты вакансионного типа.

Моделирование показало, что двухслойный электрод из дефектного силицена на серебряной подложке имеет низкую устойчивость, когда присоединение силицена к металлической поверхности осуществляется только за счет физической адсорбции. Движение иона $\mathrm{Li}^{+}$ по такому, содержащему поливакансии, силиценовому каналу возможно только при значительном зазоре между листами и большой величине напряженности электрического поля. В результате перемещения иона лития по дефектному силиценовому каналу, сцепленному с серебряной подложкой с помощью ван-дер-ваальсова взаимодействия, происходит захлопывание поливакансий, значительное искривление листов силицена и увеличение их шероховатости. Такие структурные изменения в конечном итоге разрушают электрод, делая его непригодным для использования в качестве анода литий-ионной батареи.

Вполне вероятно, что экспериментально получаемый на серебряных подложках силицен оказывается устойчивым благодаря хемосорбции ближайших к поверхности серебра атомов $\mathrm{Si}$, т.е. формированию сплава $\mathrm{Si}_{x} \mathrm{Ag}_{y}$ в месте контакта кремния с серебром. Это объясняет, почему до сих пор не удается отделить силицен от серебряной подложки. Известно также, что при осаждении атомов $\mathrm{Si}$ на медную подложку образуется сплав $\mathrm{Si}_{x} \mathrm{Cu}_{y}$.

Поиск химически инертных подложек, стабилизирующих двумерную структуру силицена, представляется актуальной задачей. Другой важной задачей исследований является разработка технологии перенесения силицена на слабо взаимодействующую с ним и не искажающую его электронную структуру подложку. Очевидно, что регулирование электронных свойств силицена за счет формирования в нем дефектов ограничено неустойчивостью дефектных структур вследствие влияния подложки или мигрирующего иона.

\section{Список литературы}

[1] P. Vogt, P. de Padova, C. Quaresima, J. Avila, E. Frantzeskakis, M.C. Asensio, A. Resta, B. Ealet, G. le Lay. Phys. Rev. Lett. 108, 155501 (2012).

[2] B.J. Feng, Z. Ding, Sh. Meng, Y. Yao, X. He, P. Cheng, L. Chen, K. Wu. Nano Lett. 12, 3507 (2012).

[3] A. Fleurence, R. Friedlein, T. Ozaki, H. Kawai, Y. Wang, Y. Yamada-Takamura. Phys. Rev. Lett. 108, 245501 (2012).

[4] L. Meng, Y. Wang, L. Zhang, Sh. Du, R. Wu, L. Li, Y. Zhang, G. Li, H. Zhou, W.A. Hofer, H.-J. Gao. Nano Lett. 13, 685 (2013).

[5] M.R. Tchalala, H. Enriquez, A.J. Mayne, A. Kara, S. Roth, M.G. Silly, A. Bendounan, F. Sirotti, T. Greber, B. Aufray, G. Dujardin, M.A. Ali, H. Oughaddou. Appl. Phys. Lett. 102, 083107 (2013).

[6] G. le Lay, B. Aufray, C. Léandri, H. Oughaddou, J.-P. Biberian, P. de Padova, M.E. Dávila, B. Ealet, A. Kara. Appl. Surf. Sci. 256, 524 (2009).

[7] F. Banhart, J. Kotakoski, A.V. Krasheninnikov. ACS Nano 5, 26 (2011).

[8] А.Е. Галашев. ЖТФ 84, 1 (2014).

[9] J.F. Guo, J.F. Zhang, H.S. Liu, Q. Zhang, J. Zhao. Nanoscale 5, 9785 (2013).

[10] V.O. Ozcelik, H.H. Gurel, S. Ciraci. Phys. Rev. B 88, 045440 (2013).

[11] А.Е. Галашев, О.Р. Рахманова. УФН 184, 1045 (2014).

[12] W. Hu, X. Wu, Z. Li, J. Yang. Nanoscale 5, 9062 (2013).

[13] A. Ambrosetti, P.L. Silvestrelli. J. Phys. Chem. C 118, 19172 (2014).

[14] G.R. Berdiyorov, F.M. Peeters. RSC Adv. 4, 1133 (2014).

[15] H. Jamgotchian, Y. Colignon, B. Ealet, B. Parditka, J.-Y. Hoarau, C. Girardeaux, B. Aufray, J.-P. Bibérian. J. Phys. 491, 012001 (2014).

[16] S. Li, Y. Wu, Y. Tu, Y. Wang, T. Jiang, W. Liu, Y. Zhao. Sci. Rep. 5, 7881 (2015).

[17] T.H. Osborn, A.A. Farajian. J. Phys. Chem. C 116, 22916 (2012). 
[18] J. Tersoff. Phys. Rev. B 49, 16349 (1994).

[19] А.Е. Галашев, О.Р. Рахманова, Ю.П. Зайков. ФТТ 58, 9, 1786 (2016).

[20] R. Yu, P. Zhai, G. Li, L. Liu. J. Electron. Mater. 41, 1465 (2012).

[21] K.-N. Chiang, C.-Y. Chou, C.-J. Wu, C.-J. Huang, M.-C. Yew. ICCES 9, 130 (2009).

[22] S.K. Das, D. Roy, S.J. Sengupta. Phys. F 7, 5 (1977).

[23] J.R. Bordin. Physica A 459, 1 (2016).

[24] K. Kawahara, T. Shirasawa, R. Arafune, C.-L. Lin, T. Takahashi, M. Kawai, N. Takagi. Surf. Sci. 623, 25 (2014).

[25] R. Wang, S. Wang, X. Wu. arXiv:1305.4789v2 [cond-mat.meshall] 23 May 2013. http://www.researchgate.net/publication/ 236871722

[26] B. Peng, F. Cheng, Z. Tao. J. Chen. Chem. Phys. 133, 034701 (2010).

[27] K. Müller, F.F. Krause, A. Béché, M. Schowalter, V. Galioit, S. Löffler, J. Verbeeck, J. Zweck, P. Schattschneider, A. Rosenauer. Nature Commun. 5, 5653 (2014).

[28] А.Е. Галашев, В.А. Полухин. ФММ 115, 742 (2014).

[29] А.Е. Галашев. ФММ 117, 258 (2016).

[30] S.J. Plimpton. Comp. Phys. 117, 1 (1995).

[31] M.R. Chavez-Castillo, M.A. Rodriguez-Meza, L. MezaMontes. Rev. Mexic. Fis. 58, 139 (2012).

[32] F.H. Stillinger, T.A. Weber. Phys. Rev. 31, 5262 (1985).

[33] G.L. Lay. www.uv.es/wsetld/archivos/Monday/ws10-Le-Lay.pdf

[34] А.Е. Галашев, В.А. Полухин. ЖФХ 88, 997 (2014).

[35] А.Е. Галашев, В.А. Полухин. ФТТ 55, 1620 (2013).

[36] А.Е. Галашев, А.А. Галашева. Химия высоких энергий 48, 142 (2014).

[37] А.Е. Галашев, И.А. Измоденов, А.Н. Новрузов, О.А. Новрузова. ФТП 41, 196 (2007).

[38] А.Е. Галашев, В.А. Полухин, И.А. Измоденов, О.Р. Рахманова. Физика и химия стекла 32, 137 (2006).

[39] M.A. Ledina, X. Liang, Y.G. Kim, J. Jung, B. Perdue, C. Tsang, M.P. Soriaga, J.L. Stickney. ECS Transact. 66, 6 129 (2015).

[40] T.P. Kaloni, M. Tahir, U. Schwingenschlögl. Sci. Rep. 3, 3192 (2013). 